\title{
Valores Inscritos na Canção Popular
}

\author{
Luiz Tatit
}

\section{Introdução}

O poder de persuasão e de interpretação da canção popular, tão analisado em seus entornos antropo-culturais e mercadológicos, possui também uma face estético-gramatical inscrita no próprio ato de composição.

Produzir canções significa produzir compatibilidades entre textos e melodias - aos quais se agregam recursos musicais de toda ordem - de modo a configurar um sentido coeso. Como ocorre em geral com as linguagens estéticas, ou sistemas semi-simbólicos ${ }^{1}$, a canção também se investe contra a famigerada arbitrariedade do signo saussuriano, buscando uma remotivação das relações entre plano da expressão e plano do conteúdo em suas respectivas progressões discursivas. Tentativa legítima de obter em processo o que não possui em sistema.

Ao mesmo tempo que a compatibilidade entre texto e melodia é apreendida sem qualquer esforço pelo ouvinte, sua explicação em termos descritivos exige um meticuloso trabalho de abstração, que compreende a identificação das categorias comuns responsáveis pela articulação dos conteúdos do texto e dos segmentos melódico-musicais. Felizmente, a fruição do ouvinte não depende de análise.

\section{Adequação ao objeto}

Grosso modo, o plano da expressão da canção popular articula-se com elementos fonológicos e elementos melódicos. Os 
primeiros mantêm a pesquisa da canção a um passo do discurso oral (da fala), enquanto os elementos melódicos atraem o analista para o viés musical. Essa dupla inclinação faz da canção um objeto de análise extremamente escorregadio e refratário à pesquisa.

Um analista que não seja ao mesmo tempo cancionista, ou ainda, que não tenha a sensibilidade prática de produção e apreensão de canções, tais como elas circulam diariamente nos meios de comunicação, muito provavelmente terminará sua pesquisa num outro campo de investigação (como musical, por exemplo), e a culpada por esse desvio será certamente a canção, que não se mostrou suficientemente boa para merecer a aplicação de um modelo tão bem construído. Há que se verificar, a todo instante, se o modelo construído ainda se refere ao mesmo objeto de análise e se ainda está adequado aos recursos de criação do compositor popular. Todos esses problemas incidem diretamente sobre a organização do plano da expressão da canção, mormente no que diz respeito à melodia.

Note-se que não se pode pensar em melodia de canção sem aproximá-la da entoação lingüística, já que ambas manifestam um fazer somático fundado numa substância de expressão vocal. Um cantor sempre diz alguma coisa com suas melodias como qualquer falante com suas entoações. Paralelamente aos investimentos modais disseminados no discurso lingüístico e no discurso da canção, ocorre um acréscimo tensivo expresso pelos contornos melódicos, onde se concentra grande parte dos conteúdos epistêmicos, cognitivos e volitivos do texto.

No caso da canção, especificamente, o tratamento especial dispensado à melodia, no sentido de estabilizá-la e precisá-la em função das acentuações fonológicas, traz a esse componente uma densidade tensiva particularmente poderosa, uma vez que sua linearidade é criada para dar conta dos mesmos conteúdos investidos no componente lingüístico. Expliquemos melhor. 


\section{Critérios tipológicos para a melodia.}

Quando examinamos uma canção popular qualquer, encontramos basicamente três modelos de construção melódica, que se manifestam como exploração tensiva dos parâmetros musicais: duração, freqüência e timbre (não considerar aqui a intensidade).

3.1. O primeiro diz respeito a um processo geral de periodicidade rítmico-melódica que favorece a produção de motivos reincidentes em forma de encadeamento. Esse tipo de progressão de elementos quase idênticos tende a demarcar uma regularidade de pulsação e de tempo forte. A importância atribuída aos ataques rítmicos repercute na escolha dos componentes fonológicos da face lingüística, dando prioridade às consoantes que funcionam como interruptoras de sonoridade. A concentração de tensividade do parâmetro duração corresponde, nesse caso, a uma redução da permanência vocálica, efeito produzido pela disseminação ágil dos acentos, e, conseqüentemente, a uma valorização das células rítmicas enquanto portadoras de pulsação e estímulos somáticos. Quanto mais dinâmico o andamento dessas células, mais sintonia adquire com relação aos movimentos regulares do nosso corpo (batimento cardíaco e inspiração/expiração por exemplo). A esse processo geral de reiteração, aceleração e regularização da pulsação rítmica, engendrando motivos bem definidos, chamaremos tematização de expressão. Geralmente, a tematização conduz a um tipo de instrumentação já comprometida com gêneros conhecidos como o samba, o rock, o bolero etc., mas em nada impede que sejam fundados novos gêneros a partir de modificações na estrutura rítmica da pulsação.

3.2. O segundo modelo caracteriza-se pelo investimento tensivo do próprio contorno em termos de ampliação do campo de tessitura melódica, das durações vocálicas e das próprias pausas entre as frases. Surge, conseqüentemente, uma tendência para os grandes saltos intervalares e para a exploração da região aguda, onde as cordas vocais manifestam fisicamente a tensividade. O prolongamento das durações, por sua vez, tem como corolário a 
desaceleração rítmica e o abrandamento da pulsação, substituindo os efeitos somáticos por efeitos psíquicos geralmente ligados a conteúdos afetivos. Como ocorre no discurso lingüístico oral, os pontos que acumulam maior densidade tensiva são os denominados tonemas $^{2}$, localizados nos finais das frases melódicas. Quando são ascendentes ou suspensivos (os que permanecem na mesma freqüência) indicam continuidade, mantendo a atenção acesa. Quando descendem, expressam terminatividade em decorrência da distensão das cordas vocais. Mas, além dos tonemas, deve-se considerar, neste segundo modelo, todo o percurso do contorno como um campo de investimento tensivo-emotivo. O prolongamento das durações, por si só, ajuda a deslocar o pólo de investimento e de concentração tensiva, pois, na medida em que neutraliza ou, pelo menos, atenua o papel das pulsações, valoriza as permanências nas vogais e, conseqüentemente, as oscilações de freqüência em todas as fases do contorno melódico. A própria dinâmica de polarização tonal, que subjaz a toda canção popular, destaca-se como importante fator de tensividade em função da valorização das freqüências. Quando em correlação com o componente lingüístico, essas oscilações poderão ser descritas, com certa precisão, nos termos das modalidades: querer, dever, crer/saber e poder. Uma tal tensividade, criada pela ampliação das freqüências e das durações, corresponde, pois, à passionalização de expressão.

3.3. O terceiro modelo de construção equivale ao processo inverso de distensão e, conseqüentemente, de desinvestimento do percurso melódico, como se esse componente tendesse a atingir um grau zero de significação, por intermédio de um tratamento que esbarra no limiar da pura entoação lingüística. Tanto a reiteração dos motivos quanto a configuração dos contornos melódicos perdem sua força tensiva, reduzindo-se às ondulações essenciais próximas ao discurso oral. A autonomia melódica, muito tênue, é assegurada por algumas reiterações esparsas e pelas inflexões asseverativas dos tonemas. A tensividade das ascendências e das suspensões indica nada mais que a continuidade do discurso, em oposição à terminatividade das descendências. As acentuações 
melódicas permanecem atreladas às acentuações lingüísticas, assim como os ataques das notas podem se desdobrar ou se reduzir em função do número de fonemas consonantais. A métrica de expressão fica a serviço da ordenação argumentativa e narrativa do conteúdo lingüístico. Trata-se de um procedimento muito semelhante ao do discurso coloquial, onde dispensamos as rimas, as aliterações e a estabilidade entoativa. Por isso, não é fácil operar melodicamente nesse limite. Uma melodia de canção jamais pode ser completamente entoativa; no entanto, o simples fato de indicar essa tendência já revela um processo que denominaremos figurativização enunciativa de expressão.

Há canções que manifestam inclinações para o primeiro modelo de construção melódica (exs.: Águas de março, Tom Jobim; Aquarela do Brasil, Ary Barroso; e $O$ que é que a baiana tem, Dorival Caymmi); outras, para o segundo (exs.: Nervos de aço, Lupicínio Rodrigues; Travessia, Milton Nascimento/Fernando Brant; e Pedaço de mim, Chico Buarque); e outras, ainda, para o terceiro modelo (exs.: Conversa de botequim, Noel Rosa/Vadico; Estatutos da gafieira, Billy Blanco; e Ouro de tolo, Raul Seixas). O mais natural, porém, é a presença dos três modelos oscilando na construção melódica de uma mesma canção. Se cantarolarmos, por exemplo, a primeira parte de Garota de Ipanema - Tom Jobim/ Vinicius de Morais (Fig. 1) ${ }^{3}$,

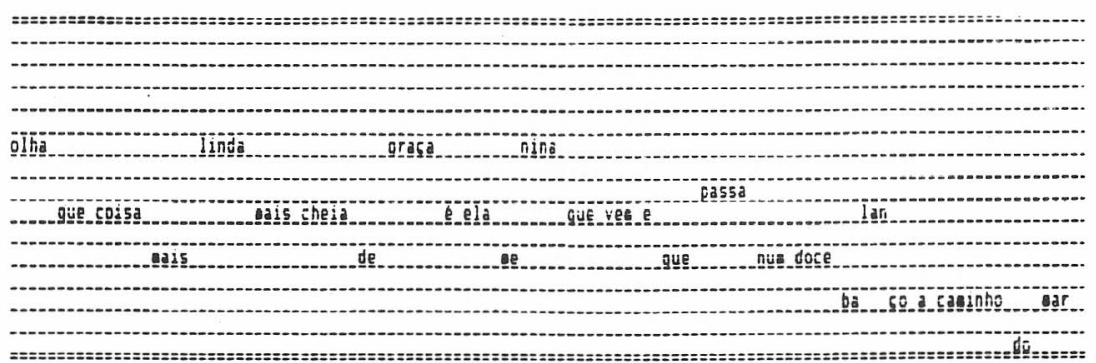


podemos identificar rapidamente o primeiro modelo referente à tematização de expressão (ou seja, um motivo fartamente reiterado). Na segunda parte, ocorre a expansão das freqüências no campo da tessitura, ao lado de um prolongamento das durações, deslocando o pólo de tensividade para o próprio desenho da curva melódica (Fig. 2):

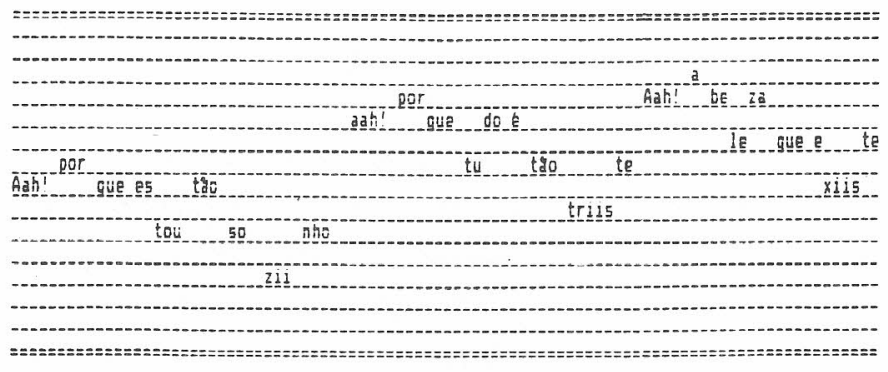

Não é dificil compreender esta oscilação de tensividade. A reiteração regular de um motivo e sua aceleração transferem o foco de investimento tensivo de cada motivo isolado para o seu encadeamento, o que neutraliza, de certa forma, o parâmetro musical relativo às freqüências, em função do privilégio dado ao parâmetro das durações (responsável pelo ritmo). De maneira inversa, o prolongamento das durações, que faz desacelerar o andamento, mais a ampliação do espaço de articulação das alturas melódicas rumo à região aguda da tessitura, atenua a pulsação rítmica e dilui a marcação do tempo forte, concentrando o foco de tensividade no desenho registrado em cada contorno melódico. Ganha relevo, portanto, o parâmetro freqüência, maior responsável pela configuração do perfil da curva.

Uma vez que todos os parâmetros musicais (timbre, intensidade, duração e freqüência) manifestam-se a partir da emissão de um único som, diremos que a oscilação entre duração e freqüência se dá em termos de maior ou menor acúmulo de densidade tensiva. Assim sendo, a distensão simultânea dos dois parâmetros pode evidenciar a presença do timbre vocal, elemento especificador da instância de enunciação, que vem reforçar o terceiro modelo de construção melódica, a que chamamos figurativização enunciativa. 
A função normalmente desempenhada pelo timbre, entretanto, é a - de ponte de ligação entre as zonas de densidade tensiva dos enunciados melódicos e o sujeito da enunciação que, na canção popular, vem manifestado pelo cantor.

\section{A relação com o texto}

Esses três modelos de construção melódica da canção tornam-se ainda mais interessantes quando verificamos sua compatibilidade com o desenvolvimento do componente lingüístico.

À tematização melódica corresponde, em geral, a tematização narrativa. Um outro tipo de reiteração, de natureza sêmica, qualifica o /ser/ de um actante ${ }^{4}$, dotando-o de aptidões que se desenvolvem em performances (/fazer/) geralmente pragmáticas. Simultaneamente, este actante é atorializado ${ }^{5}$ com inúmeros traços figurativos vinculados ao que a semiótica chama de expressão do mundo natural. Tudo ocorre como se a concretização do motivo melódico representasse a manifestação do ator ou da figura discursiva.

À passionalização melódica corresponde a passsionalização como estado modal narrativo. Nesse sentido, a tensividade contida nos contornos melódicos representa, no plano da expressão, a tensividade decorrente das disjunções e conjunções dos actantes narrativos do plano do conteúdo. Não é à toa que quase todas as canções do segundo modelo tratam do tema da separação ou da união amorosa.

À figurativização melódica, finalmente, corresponde o aumento da deitização $o^{6}$ lingüística. A distensão dos parâmetros duração e freqüência visa romper, até certo ponto, com a autonomia do enunciado musical, atraindo a atenção para a situação enunciativa. Esta tendência ocasiona no componente lingüístico um acréscimo considerável dos imperativos, vocativos, demonstrativos e de todos os elementos que servem para dar impressão de presentificação enunciativa. Este processo atinge o auge quando o cantor, durante um samba de breque por exemplo, interrompe a melodia progra- 
mada e passa a improvisar uma fala, cujas entoações, exclusivamente circunstanciais, jamais poderão ser novamente repetidas.

Entretanto, o papel mais significativo da figurativização na canção popular não se refere aos casos de distensão melódica e sim à presença da instância enunciativa (relativa à enunciação) na articulação das tensividades enuncivas (relativas aos enunciados). O timbre da entoação vem sempre realizado por um intérprete-cantor que dosa os investimentos tensivos de acordo com seu estilo de tratamento no plano da manifestação, firmando a cada execução um novo contrato enunciativo com o ouvinte. A partir desse contrato, os pólos de tensividade propostos pela composição são relativizados e reescalonados em novas bases fiduciárias. Tudo depende da habilidade persuasiva do intérprete no manejo das tensividades já sugeridas na composição. Num sentido mais abstrato, podemos dizer que o parâmetro timbre regula, numa perspectiva enunciativa, as oscilações de tensividade entre os parâmetros duração e freqüência dos enunciados melódicos.

\section{Projeto enunciativo}

Chegamos, assim, àquilo que podemos chamar de projeto enunciativo de uma canção. Todas as possibilidades oscilatórias entre tensões temáticas e tensões passionais, bem como o processo de desativação dessas tensões, estão inscritas, de algum modo, no seu projeto enunciativo. Quando ouvimos diferentes execuções de uma mesma composição, entramos em contato com diferentes interpretações do mesmo projeto geral criado pelo cancionista. A própria noção de intérprete, geralmente próxima à de cantor, ganha, nesse sentido, nova dimensão: o intérprete é também aquele que realiza a primeira leitura interpretativa do projeto enunciativo do compositor, orientando, com sua intermediação, a segunda leitura que será praticada pelo ouvinte.

O projeto enunciativo pode ser desdobrado em projeto entoativo (recursos investidos na melodia) e projeto narrativo (recursos inves- 
tidos no texto). Uma canção tradicionalmente interpretada numa linha temática pode conter, em seu projeto entoativo, alguns traços de prolongamento vocálico ou de pausas que, uma vez valorizados, transferem toda a canção para uma linha de leitura passional. Da mesma forma, se seu texto - além da exaltação de seus personagens, objetos e acontecimentos - configura alguma situação passiva, ou um sentimento de perda e carência, tais características podem se aflorar em ressonância à nova inflexão melódica.

Uma canção como Felicidade - Lupicínio Rodrigues -, por exemplo, conheceu, até o momento, pelo menos duas versões interpretativas diametralmente opostas: a do Quarteto Quitandinha em 1947 e a de Caetano Veloso em 1974. A primeira destaca as tematizações investidas no projeto enunciativo. No projeto entoativo, temos as seqüências descendentes que, em versão acelerada, perfazem um encadeamento recorrente típico da tematização (Fig. 3):

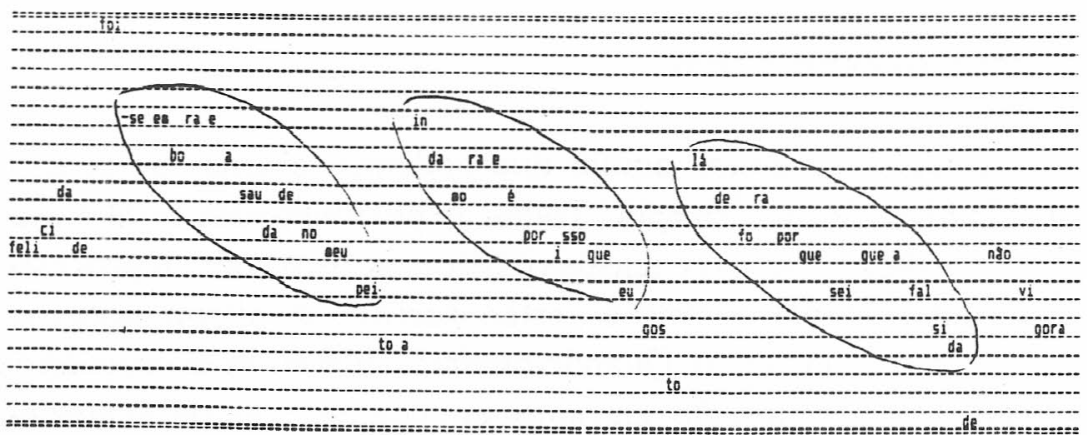


E, no interior dessas seqüências, outras células se sobressaem como alinhavos rítmicos que garantem a expansão dos temas-chaves (em destaque pela ampliação simultânea de duração e altura) por todo o encadeamento (Fig. 4).

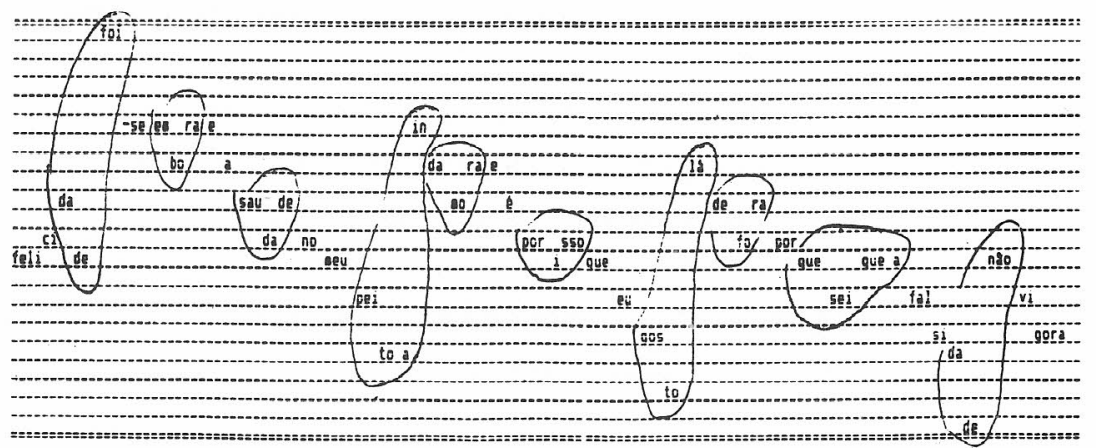

A segunda parte nos traz uma reiteração temática explícita que dispensa comentários (Fig. 5):

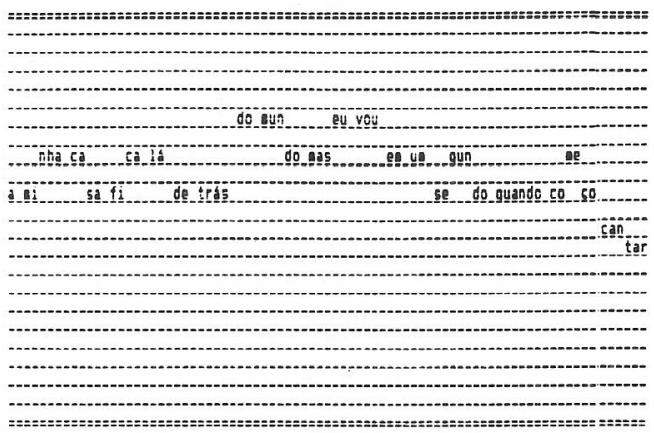

Quanto ao projeto narrativo do texto, a valorização recai, nessa versão, sobre os conteúdos que apontam para uma direcionalidade resolvida. Assim como a melodia constrói um itinerário previsível, através de células reiterativas, o texto revela as conjunções eufóricas do actante sujeito EU ("eu gosto lá de fora..." / "a minha casa...") e a passagem livre que leva o sujeito até seu objeto de valor ("mas eu vou em um segundo..."). O sujeito ainda conta com dois instru- 
mentos do poder/, manifestados pelo "canto" ("... eu vou em um segundo quando começo a cantar") e pelo "pensamento" ("como é que a gente voa quando começa a pensar"), adjuvantes infalíveis de suas ações.

A versão de Caetano Veloso apresenta, entre outras coisas, um significativo alongamento vocálico que repercute imediatamente na individualização dos contornos melódicos (e conseqüente suspensão do encadeamento). Acontece que o projeto entoativo desta canção permite também uma leitura passional a partir de uma simples desaceleração. Sobre a base de um campo de tessitura extremamente amplo (22 semitons), há uma programação para saltos intervalares ascendentes de 12 semitons e para as retenções vocálicas nas sílabas assinaladas abaixo (Fig. 6):

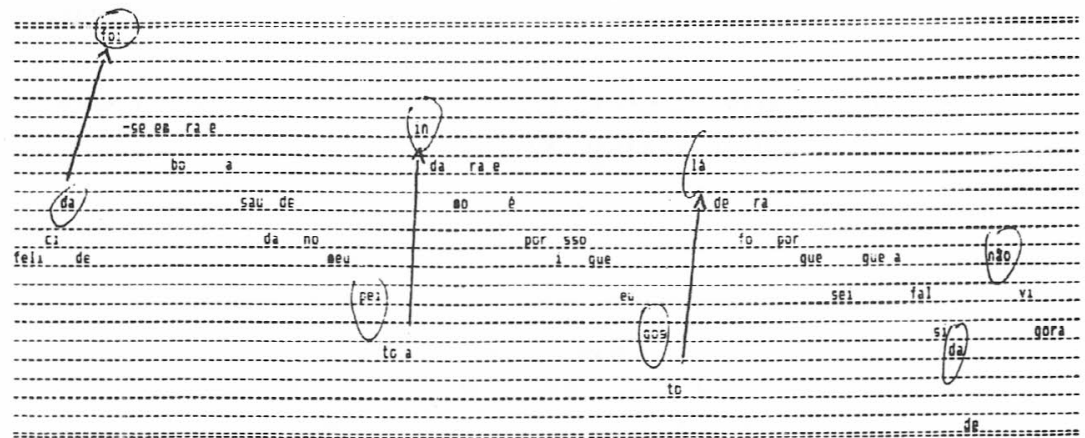

Para manter o efeito durante a segunda parte - onde a programação é eminentemente temática - o arranjo instrumental sustenta o caráter passional com as amplas inflexões e amplas durações do estribilho do Luar do sertão - Catulo da Paixão Cearense - soladas ao fundo.

Essa sutil inclinação para os recursos passionais, também inscritos no projeto entoativo de Felicidade, é suficiente para "liberar" do texto os conteúdos emocionais do projeto narrativo ocultados na primeira versão. A perda da "felicidade" e a conjunção com um valor disfórico - a "saudade" (que implicita a disjunção com o valor realmente desejado) -, vêm à tona e se expandem sobre os demais conteúdos, tornando-os recessivos. 
O projeto enunciativo criado pelo compositor representa, em primeiro lugar, uma seleção inicial dos valores temporais, missivos ${ }^{7}$, que estão na base de toda produção de sentido. A opção pela retenção do tempo significa um compromisso com os valores remissivos manifestados pela lembrança e pela expectativa. A opção pela distensão do tempo se transforma em satisfação eufórica com os valores emissivos. São paradas e continuidades que fazem oscilar a - elasticidade do "continuum" temporal e que se convertem em programação comum ao plano da expressão e ao plano do conteúdo ${ }^{8}$.

No exemplo de Felicidade, os valores emissivos foram ressaltados na versão do Quarteto Quitandinha pela exploração das virtualidades temáticas (melódicas e lingüísticas) inscritas no projeto enunciativo. Na versão de Caetano Veloso, os valores remissivos do mesmo projeto foram traduzidos em termos de passionalização (melódica e lingüística). A solução no tratamento desses valores temporais depende, evidentemente, de cada composição.

O projeto enunciativo contém as possibilidades persuasivas de uma canção que deverão ser absorvidas e selecionadas por um intérprete-cantor e, por fim, apresentadas ao ouvinte para a última fase interpretativa. O estudo deste projeto é, a nosso ver, o núcleo principal de investigação das estratégias persuasivas do próprio objeto de análise. Tal enfoque preencheria talvez boa parte da lacuna deixada pelo abandono precoce (salvo honrosas exceções) das pesquisas sobre a linguagem, em função de suas causas e conseqüências no meio sócio-cultural.

\section{NOTAS}

1. Semi-simbólicos são os sistemas significantes que não possuem a mesma conformidade entre as unidades do plano da expressão e as do plano do conteúdo, como ocorre no sistema lingüístico (considerado, em semiótica, sistema simbólico por excelência). As relações entre os dois planos são estabelecidas por categorias. Por exemplo, a categoria que articula ascendência e descendência melódicas, no plano da expressão, pode estar relacionada à categoria que articula, no plano do conteúdo, as noções de prossecução e conclusão. 
2. Os tonemas, segundo Navarro Tomas (Manual de entonación española, México, Málaga, 1966), correspondem às terminações melódicas das frases enunciativas. Neles se concentra a maior parte do teor significativo das unidades entoativas.

3. O semioticista Claude Zilberberg emprega o termo missivo para designar a categoria que traduz a tensão temporal ora num viés expectante, remissivo, ora num viés originante, emissivo. Ver, principalmente, seu capítulo intitulado "Pour introduire le faire missif", in Raison et poétique du sens, PUF, 1988.

4. Desenvolvemos este tema no artigo intitulado "Tempo e tensividade na análise da canção", in Cadernos de Estudo: Análise Musical III, São Paulo, Atravez, out. 1990.

5. A noção de atorialização refere-se à passagem do nível narrativo ao nível discursivo, quando o actante ganha investimentos semânticos e se transforma num ator com todo o enriquecimento de sentido próprio desse processo.

6. A deitização é o processo pelo qual os enunciados se reportam à instância de enunciação. por intermédio dos dêiticos (tempo, espaço, demonstrativos, imperativos, vocativos...) o enunciador se projeta no discurso e simula a presença da enunciação no enunciado.

7. O semioticista Claude Zilberberg emprega o termo missivo para designar a categoria que traduz a tensão temporal ora num viés expectante, remissivo, ora num viés originante, emissivo. Ver, principalmente, seu capítulo intitulado "Pour introduire le faire missif", in Raison et poétique du sens, PUF, 1988.

8. Desenvolvemos este tema no artigo intitulado "Tempo e tensividade na análise da canção", in Cadernos de Estudo: Análise Musical III, São Paulo, Atravez, out. 1990.

Luiz Tatit é Professor no Departamento de Lingüística da F.F.L.C.H. da Universidade de São Paulo. 